Relations industrielles

Industrial Relations

\title{
L'A.P.I. en congrès à Montréal
}

\section{Moreau}

Volume 6, numéro 1, décembre 1950

URI : https://id.erudit.org/iderudit/1023248ar

DOI : https://doi.org/10.7202/1023248ar

Aller au sommaire du numéro

Éditeur(s)

Département des relations industrielles de l’Université Laval

ISSN

0034-379X (imprimé)

1703-8138 (numérique)

Découvrir la revue

Citer cette note

Moreau, L. (1950). L'A.P.I. en congrès à Montréal. Relations industrielles /

Industrial Relations, 6(1), 28-28. https://doi.org/10.7202/1023248ar

Tous droits réservés @ C Département des relations industrielles de l’Université Laval, 1950
Ce document est protégé par la loi sur le droit d'auteur. L'utilisation des services d'Érudit (y compris la reproduction) est assujettie à sa politique d'utilisation que vous pouvez consulter en ligne.

https://apropos.erudit.org/fr/usagers/politique-dutilisation/ 


\section{L'A.P.I. en congrès à Montréal}

Les 30 et 31 octobre derniers, l'Association Professionnelle des Industriels tenait son 6ème Congrès annuel à Montréal. Le thème à l'étude était le suivant: \& La sécurité économique et sociale ». Disons immédiatement que ces journées d'études et de délibérations ont eu un franc succès. Elles ont groupé quelque 150 des trois cents patrons qui sont membres actifs de la plus importante association patronale catholique de la province de Québec.

Les administrateurs de l'A.P.I. ont été particulièrement heureux dans le choix des conférenciers pour le banquet annuel de l'Association et pour les déjeuners-causeries.

Me P.-E. Côté, député de Verdun, secrétaire parlementaire de l'Honorable Ministre fédéral du Travail, parla des Comités mixtes de production, comme moyen indispensable de «conquérir la paix industrielle ».

M. Esdras Minville, doyen de la Faculté des sciences sociales de l'Université de Montréal, présenta quelques « réflexions sur Thomme d'affaires canadien-français $\gg$. M. Minville passa en revue les relations que Ihomme d'affaires doit entretenir avec la clientèle, avec son personnel, avec ses confrères industriels et avec les pouvoirs publics. Ces relations de l'homme d'affaires avec les groupes précités doivent se régler selon les normes de la justice sociale, ce qui nécessitera un long travail de réflexion. Il faut complètement repenser le monde économique. Qui est prêt à le faire présentement? Ce travail n'appartient pas aux gouvernants. Par ailleurs, les hommes d'affaires ne sont pas prêts à l'entreprendre. M. Minville souhaita une franche collaboration entre les hommes d'affaires et les professeurs d'universités qui consacrent leurs travaux à l'étude des problèmes du monde industriel et commercial.

M. Minville dit que les entreprises ont dépassé le stage des risques économiques. Elles en sont présentement aux risques sociaux. Mais il faut une union des industriels pour mettre en application des plans de sécurité sociale. S'il en allait autrement, les patrons les mieux disposés seraient pénalisés du fait de leurs bonnes dispositions. Aussi M. Minville souhaita que l'A.P.I. soit de plus en plus florissante.

M. l'abbé J.-Bte Desrosiers, p.s.s., Directeur de l'Institut Pie XI, parla de l'organisation professionnelle dans les documents pontificaux. C'est un sujet qui ne manque pas d'à-propos, car l'on sait comment l'employeur, laissé à lui-même, pourrait être porté à contrecarrer de toute façon la liberté d'association et la liberté d'action syndicale de ses employés. L'A.P.I. est une association confessionnelle, qui se ré- clame de la Doctrine sociale de l'Eglise. Elle a passé une résolution d̀ ce sujet, d son récent congrès: \& L'A.P.I. réaffirme la nécessité de sauvegarder entièrement le troit des ouvriers au travail et leur liberté syndicale. \$

Un conférencier du congrès qui fut remarqué, est $M$. W.J. Whitehead, Directeurgérant de la Wabasso Cotton Co. Ltd. Il avait intitulé sa conférence: «Les expériences sociales de la Wabasso Cotton Co.

S'exprimant dans un parfait français, $M$. Whitehead exposa l'application faite dans ses usines du plan Rucker de participation ouvrière aux revenus de la transformation.

* Après beaucoup d'étude et d'expérience, j'en suis venu à la conclusion que seul un système de partage, tenant compte d'abord de ce qui peut être obtenu du consommateur, de ce qui est nécessaire à la stabilité et au progrès de l'entreprise et de la valeur humaine des efforts de la main-d'oeuvre, peut nous permettre l'accomplissement de nos obligations et nous assurer la paix sociale. Ce système, je l'ai trouvé dans le plan de participation aux revenus de la transformation, conçu par M. Rucker. M. Whitehead a exposé pendant une heure la technique du plan et a répondu aux questions qu'on lui a posées. Souhaitons que les étudiants des Facultés immédiatement concernées de l'Université Laval aient l'avantage d'entendre ce patron, qui, bien qu'il soit d'une confession religieuse différente de la nôtre, n'en a pas laissé, dans sa grande probité intellectuelle, de mettre en évidence la Lettre de la hiérarchie catholique de la province de Qué bec. « Tous les patrons chrétiens conviendront avec nous, dit-il, qu'elle (cette Lettre) doit non seulement recevoir notre accueil respectueux, mais faire l'objet de nos études et inspirer notre travail de citoyens ayant des responsabilités sociales extraordinaires.

L'A.P.I. peut être heureuse du Congrès qu'elle vient de tenir. M. J.-L. Héon, président du Comité provincial de recrutement, fit un appel pressant aux membres actuels pour recruter deux cents nouvelles adhésions à l'A.P.I. au cours de la prochaine année.

Le nouveau président de l'A.P.I. est $M$. Horace Boivin, président de Granby Elastic Web of Canada Limited et maire de Granby.

Le Département des relations industrielles de la Faculté des sciences sociales de Laval, était représenté par son Secrétaire.

L. Moreau, ptre Etudiant en relations industrielles 